Praxis : Jurnal Sains, Teknologi, Masyarakat dan Jejaring | Vol. 3 | No. 2 | Maret 2021

\title{
Deskripsi Organizational Citizenship Behavior Perawat Untuk Lansia Di Wisma Harapan Asri Yayasan Mardiwijana Semarang”
}

\author{
Yulius Susilo $^{1}$ : Rudi Elyadi ${ }^{2}$ \\ Program Studi Manajemen, Fakultas Ekonomi dan Bisnis \\ Universitas Katolik Soegijapranata \\ email: brsusilocsa@gmail.com ${ }^{1}$; rudy@unika.ac.id.com²
}

\begin{abstract}
The number of elderly population in Indonesia from year to year is increasing, so it is needed a place and assistance services for elderly citizens. Wisma Harapan Asri Semarang provides services so that the elderly residents feel comfortable and at ease. The nurses for the elderly have the role of assisting and serving elderly citizens. The performance of the nurses has an important role for the quality of the services of the elderly homestead. Improved services will be better if the nurses have the attitude and actions of the Organizational Citizenship Behavior $(O C B)$ at work.

This study aimed to determine the $O C B$ of nurses based on five dimensions of $O C B$. The five dimensions of $O C B$ according to Organ are: altruism, courtesy, conscientiousness, sportmanship, and civic virtue. Descriptive qualitative research method to describe the OCB actions of nurses. The results showed OCB of nurses in the high category. An effort to improve the performance of nurses in accordance with the five dimensions of OCB. Also efforts to improve the services of nurses to meet the needs of the elderly. This research is useful for Wisma Harapan Asri in an effort to shape the behavior of nurses to provide the best service for the elderly.
\end{abstract}

Keywords: Organizational Citizenship Behavior (OCB), nurses for the elderly, five dimensions of $O C B$.

\section{PENDAHULUAN \\ Latar Belakang}

Realitas yang terjadi di negara Indonesia menunjukkan adanya pertumbuhan jumlah warga yang berusia lanjut. Melihat peningkatan penduduk lansia ini, maka perlu kesiapan untuk menyediakan tempat bagi warga lansia berupa panti atau wisma lansia. Di samping itu pula dibutuhkan usaha memberikan pelayanan pendampingan untuk warga lansia demi kesejahteraan hidup mereka.

Wisma Harapan Asri yang bernaung dalam Yayasan Mardiwijana Semarang adalah lembaga yang memberi pendampingan untuk orang lanjut usia (lansia). Organisasi ini mempunyai tujuan untuk melayani orang-orang lanjut usia supaya mendapatkan kehidupan yang penuh kasih, kedamaian dan harmonis di masa senjanya. Segenap pengurus wisma berusaha memberikan pelayanan terbaik bagi para penghuni lansia supaya mereka merasa nyaman tinggal di wisma ini. Agar dapat memberikan pelayanan yang optimal bagi lansia, dibutuhkan sumber daya yang mampu memberikan pendampingan terbaik.

Di antara seluruh tenaga yang melayani lansia, perawat merupakan salah satu bagian penting dalam memberikan pelayanan pendampingan. Para perawat 
menjadi penentu utama untuk memberikan pelayanan terbaik bagi lansia, karena perawat berinteraksi secara langsung dengan para penghuni lansia. Perawat juga mempunyai peran penting yang menentukan kualitas pelayanan di wisma ini. Maka dari itu para perawat diharapkan dapat memberikan pelayanan yang optimal dan mempunyai semangat kepedulian yang lebih pada para penghuni lansia.

Dalam melaksanakan tanggung jawab bidang keperawatan itu, para perawat melakukan pekerjaan berdasarkan uraian tugas yang telah ditentukan dalam SOP (Standard Operational Procedure). Diketahui bahwa dalam kondisi tertentu terdapat peningkatan jumlah pekerjaan yang menuntut penyelesaian dengan segera. Sebaiknya para perawat tidak hanya bekerja sesuai SOP tetapi juga membutuhkan Organizational Citizenship Behavior $(O C B)$ dalam memberikan pelayanan untuk lansia. $O C B$ adalah perilaku individu yang bersifat sukarela, yang secara tidak langsung atau secara eksplisit diakui oleh sistem reward formal, dan memberi kontribusi pada efektivitas dan efisiensi fungsi dalam organisasi (Organ, 2006 dalam Akira \& Devi Jatmika, 2015).

\section{Perumusan Masalah}

Bagaimana deskripsi Organizational Citizenship Behavior (OCB) perawat lansia di Wisma Harapan Asri Semarang berdasarkan lima dimensi $O C B$, serta upaya untuk meningkatan pelayanan bagi penghuni lansia.

\section{Tujuan Penelitian}

Untuk mengetahui, bagaimana deskripsi Organizational Citizenship Behavior $(O C B)$ perawat lansia di Wisma Harapan Asri Semarang, serta upaya untuk meningkatkan pelayanan bagi penghuni lansia

\section{Manfaat Penelitian}

Diharapkan dapat berguna untuk pengembangan ilmu Manajemen Sumber Daya Manusia dalam bentuk penelitian mengenai Organizational Citizenship Behavior (OCB), serta sebagai masukan untuk pengurus Wisma Lansia Harapan Asri dalam merumuskan kebijakan dalam upaya untuk meningkatkan perilaku Organizational Citizenship Behavior $(O C B)$ para perawat.

\section{LANDASAN TEORITIS}

\section{Pengertian Organizational Citizenship Behavior (OCB)}

Menurut Organ dan Konovsky (Sahrah, 2010; dalam Akira \& Devi Jatmika, 2015:53), Organizational Citizenship Behavior $(O C B)$ adalah perilaku prososial atau tindakan ekstra yang melebihi deskripsi peran yang ditetapkan suatu organisasi. Organisasi akan dapat mencapai tujuannya apabila karyawan tidak hanya melaksanakan tanggung jawab pokoknya saja, tetapi juga bersedia melaksanakan tugas selain pekerjaan utamanya, antara lain rela membantu pekerjaan karyawan lain, memberikan pendapat dan pemikiran, suka bekerja sama, menunjukkan partisipasi aktif, memberikan pelayanan ekstra untuk orang yang dilayani dan dapat menggunakan waktu kerja secara efektif. Perilaku prososial atau tindakan ekstra yang melebihi deskripsi peran yang ditentukan dalam organisasi atau perusahaan itu disebut sebagai $O C B$ (Ahdiyana, 2010).

\section{Dimensi Organizational Citizenship Behavior (OCB)}

Menurut Organ (2006; dalam Akira \& Devi Jatmika, 2015:53), terdapat lima dimensi dalam $O C B$ antara lain :

a. Altruism, yaitu perilaku sukarela pada karyawan yang memiliki efek membantu orang lain yang spesifik dengan masalah organisasional yang relevan. 
b. Courtesy, yaitu perilaku sukarela dalam diri setiap individu untuk mencegah timbulnya masalah dengan orang lain sehubungan dengan pekerjaannya.

c. Sportmanship, yaitu keinginan dari karyawan untuk mentolerir kekurangan dari kondisi ideal tanpa mengeluh.

d. Civic virtue, yaitu perilaku pada bagian dari individu yang menunjukkan bahwa ia / dia bertanggung jawab berpartisipasi dalam, terlibat dalam, atau prihatin dengan kehidupan perusahaan.

e. Conscientiousness, yaitu perilaku sukarela pada diri karyawan untuk melampaui persyaratan minimum peran organisasi di bidang kehadiran, mematuhi aturan dan peraturan, mengambil istirahat, dan sebagainya.

Dalam penelitian ini konsep Organizational Citizenship Behavior yang digunakan adalah konsep yang telah dikemukakan Organ. Ketiga dimensi $O C B$ menurut Graham terdapat dalam kelima dimensi $O C B$ menurut Organ. Alasan menggunakan konsep Organizational Citizenship Behavior menurut Organ dengan lima dimensi $O C B$ karena konsep yang dikemukakan Organ lebih menyeluruh dan mencakup keseluruhan dimensi dari konsep teori lainnya.

\section{Kebutuhan Lanjut Usia}

Setiap individu tentunya mempunyai harapan dapat mencapai hidup sampai usia lanjut dengan penuh kebahagiaan. Kebahagiaan dapat terwujud apabila:

(1) Adanya rasa kepuasan dalam hidupnya;

(2) Bagaimana sikap seseorang dalam menghadapi permasalahan hidupnya; (3) Banyaknya kegiatan atau aktivitas yang dilakukan sehingga dalam usia lanjut tidak merasa kesepian. (4) Komposisi sosial, bagaimana lanjut usia bisa berintegrasi dengan keluarga dan lingkungan sosial (Siti Rahayu Haditomo dalam Setyaningrum, 2012).

\section{Kerangka Pikir Penelitian}

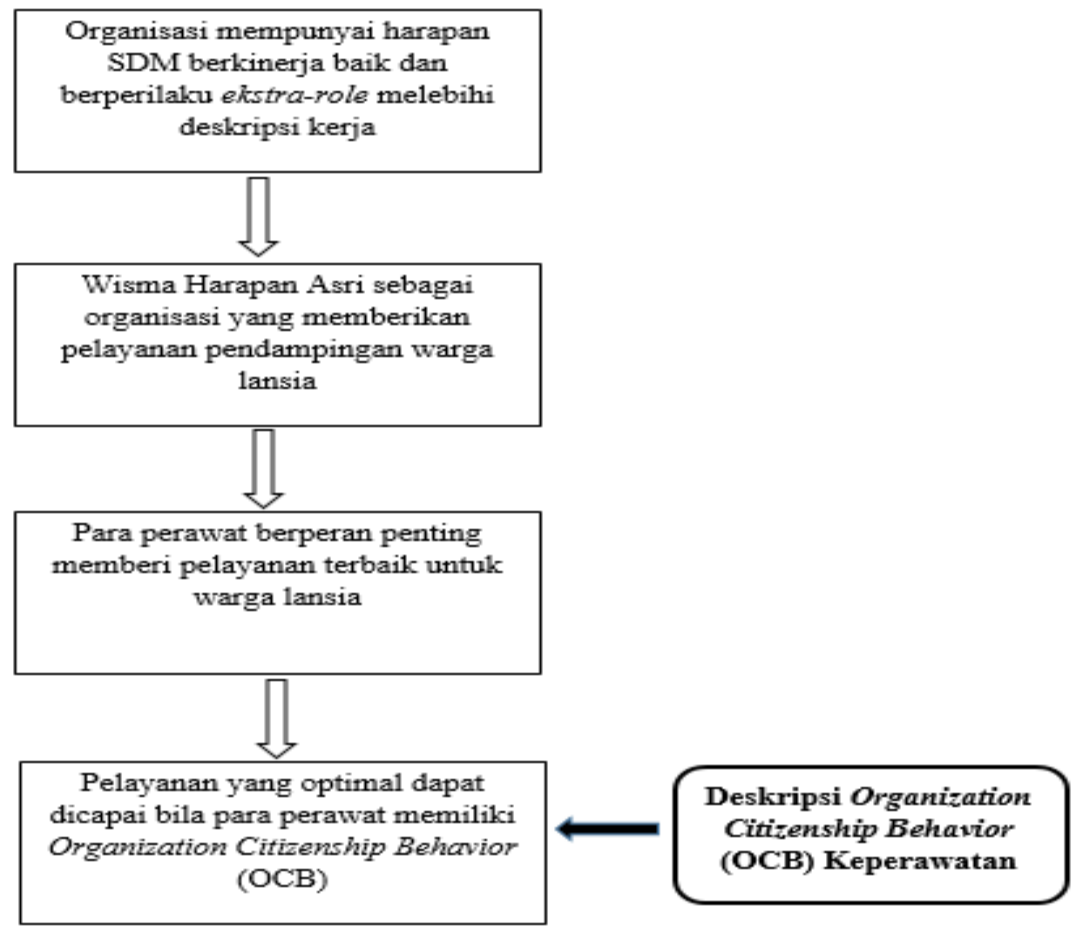

Gambar 1. Bagan Kerangka Pikir Penelitian 


\section{METODE PENELITIAN}

\section{Obyek dan Lokasi Penelitian}

Obyek dalam penelitian ini adalah semua karyawan di bagian keperawatan Wisma Harapan Asri yakni para perawat yang memberikan pelayanan pendampingan untuk para penghuni lanjut usia. Wisma Harapan Asri yang bernaung di bawah Yayasan Mardiwijana ini terletak di Jl. Tusam Raya 2A, Pedalangan-Banyumanik, Semarang.

\section{Populasi Penelitian}

Populasi dalam penelitian ini seluruh karyawan bagian keperawatan yang berjumlah sebanyak 20 orang, dan seluruh populasi dijadikan sampel.

\section{Jenis dan Sumber Data dan Teknik Pengumpulan}

Jenis data yang digunakan adalah data primer, yang diperoleh berasal dari sumber langsung yakni para perawat wisma lansia, dan pengumpulan data dilakukan dengan menggunakan kuesioner.

\begin{abstract}
Alat Analisis Data
Dalam penelitian ini analisis data yang digunakan adalah analisis deskriptif. dengan cara mendeskripsikan atau menggambarkan data yang telah terkumpul sebagaimana adanya tanpa bermaksud membuat kesimpulan yang berlaku untuk umum atau generalisasi. Penentuan kategori berdasarkan indeks :

Indeks $=1,00-2,33 ;$ kategori Rendah

Indeks $=2,34-3,67 ;$ kategori Sedang

Indeks $=3,68-5,00 ;$ kategori Tinggi
\end{abstract}

\section{ANALISIS DAN PEMBAHASAN \\ Tanggapan Perawat terhadap Organizational Citizenship Behavior $(\mathrm{OCB})$}

Berikut ini akan dijelaskan tanggapan responden mengenai Organizational Citizensip Behavior berdasarkan 5 dimensi, yang disajikan pada tabel.1 sampai denag tabel.5 sebagai berikut:

Tabel 1. Hasil Perhitungan Dimensi Altruism

\begin{tabular}{|c|c|c|c|c|c|c|c|c|}
\hline \multirow{2}{*}{ No } & \multirow{2}{*}{ Pernyataan } & \multicolumn{5}{|c|}{ Pilihan Jawaban } & \multirow{2}{*}{ Indek } & \multirow{2}{*}{ Kategori } \\
\hline & & STS & TS & $\mathbf{N}$ & $\mathbf{S}$ & SS & & \\
\hline 1. & $\begin{array}{l}\text { Saya selalu siap membantu } \\
\text { ketika ada rekan kerja } \\
\text { yang membutuhkan } \\
\text { bantuan }\end{array}$ & & & $\begin{array}{c}2 \\
(6)\end{array}$ & $\begin{array}{c}10 \\
(40)\end{array}$ & $\begin{array}{c}8 \\
(40)\end{array}$ & 4,30 & Tinggi \\
\hline 2. & $\begin{array}{l}\text { Saya akan menggantikan } \\
\text { peran rekan kerja yang } \\
\text { tidak masuk kerja. }\end{array}$ & & $\begin{array}{c}1 \\
\text { (2) }\end{array}$ & $\begin{array}{c}10 \\
(30)\end{array}$ & $\begin{array}{c}6 \\
(24)\end{array}$ & $\begin{array}{c}3 \\
(15)\end{array}$ & 3,55 & Sedang \\
\hline 3. & $\begin{array}{l}\text { Saya bersedia bekerja } \\
\text { lembur untuk membantu } \\
\text { rekan kerja menyelesaikan } \\
\text { pekerjaannya meskipun } \\
\text { saya tidak mendapatkan } \\
\text { imbalan. }\end{array}$ & $\begin{array}{c}2 \\
(2)\end{array}$ & $\begin{array}{c}4 \\
(8)\end{array}$ & $\begin{array}{c}7 \\
(21)\end{array}$ & $\begin{array}{c}5 \\
(20)\end{array}$ & $\begin{array}{c}2 \\
(10)\end{array}$ & 3,05 & Sedang \\
\hline
\end{tabular}


Praxis : Jurnal Sains, Teknologi, Masyarakat dan Jejaring | Vol. 3 | No. 2 | Maret 2021

\begin{tabular}{|l|l|l|c|c|c|c|c|c|}
\hline 4. & $\begin{array}{l}\text { Saya memberikan waktu } \\
\text { dan tenaga saya untuk } \\
\text { kepentingan kelompok } \\
\text { walaupun tidak ada } \\
\text { keuntungan langsung bagi } \\
\text { saya }\end{array}$ & $\begin{array}{c}1 \\
(2)\end{array}$ & $\begin{array}{c}7 \\
(21)\end{array}$ & $\begin{array}{c}8 \\
(32)\end{array}$ & $\begin{array}{c}4 \\
(20)\end{array}$ & 3,75 & Tinggi \\
\hline & Indeks Altruism & $\mathbf{3 , 6 6}$ & Sedang \\
\hline
\end{tabular}

Sumber: Data Primer yang diolah

\section{Dimensi Altruism}

Berdasarkan tabel.1 diatas, dapat dijelaskan bahwa dimensi Altruism memilika nilai indek rata - rata 3,66 termasuk katarori Sedang, artinya perilaku sukarela pada karyawan yang memiliki efek membantu orang lain yang spesifik dengan masalah organisasional yang relevan belum sepenuhnya dilakukan oleh para perawat, hal ini terlihat adanya perawat yang belum bersedia /ragu untuk menggantikan peran rekan kerja yang tidak masuk kerja dan bayak perawat yang belum bersedia bekerja lembur untuk membantu rekan kerja menyelesaikan pekerjaannya. Walaupun demikian masih ada juga perawan yang menyatakan bersedian membantu rekan kerjanya yang membutuhkan bantuan dan juga bersediana untuk emembantu kelompok walaupun tidak mendapatkan keuntungan.

Tabel 2. Hasil Perhitungan Dimensi Courtesy

\begin{tabular}{|c|c|c|c|c|c|c|c|c|}
\hline \multirow{3}{*}{ No } & \multirow{3}{*}{ Pernyataan } & \multirow{2}{*}{\multicolumn{5}{|c|}{ Pilihan Jawaban }} & \multirow{3}{*}{ Indek } & \multirow{3}{*}{ Kategori } \\
\hline & & & & & & & & \\
\hline & & STS & TS & $\mathbf{N}$ & $\mathbf{S}$ & SS & & \\
\hline 1. & $\begin{array}{l}\text { Saya selalu menjaga } \\
\text { hubungan baik dengan } \\
\text { sesama karyawan }\end{array}$ & & & $\begin{array}{c}3 \\
(9)\end{array}$ & $\begin{array}{c}7 \\
(28)\end{array}$ & $\begin{array}{c}10 \\
(50)\end{array}$ & 4,35 & Tinggi \\
\hline 2. & $\begin{array}{l}\text { Saya selalu membuka diri } \\
\text { bagi rekan kerja yang ingin } \\
\text { bertukar pikiran }\end{array}$ & & & $\begin{array}{c}1 \\
(3)\end{array}$ & $\begin{array}{c}11 \\
(44)\end{array}$ & $\begin{array}{c}8 \\
(40)\end{array}$ & 4,35 & Tinggi \\
\hline 3. & $\begin{array}{l}\text { Saya selalu mengingatkan } \\
\text { rekan kerja agar tidak lupa } \\
\text { menyelesaikan tugasnya }\end{array}$ & & & $\begin{array}{c}7 \\
(21)\end{array}$ & $\begin{array}{l}13 \\
(52)\end{array}$ & & 3,65 & Sedang \\
\hline 4. & $\begin{array}{l}\text { Saya sering berdiskusi } \\
\text { dengan rekan kerja terkait } \\
\text { masalah pekerjaan }\end{array}$ & & & $\begin{array}{c}3 \\
(9)\end{array}$ & $\begin{array}{c}11 \\
(44)\end{array}$ & $\begin{array}{c}6 \\
(30)\end{array}$ & 4,15 & Tinggi \\
\hline & \multicolumn{6}{|c|}{ Indeks Courtesy } & 4,12 & Tinggi \\
\hline
\end{tabular}

Sumber: Data primer yang diolah

\section{Dimensi Courtesy}

Berdasarkan pada Tabel.2 diatas tangapan responden/ perawat untuk Dimensi
Courtesy nilai indeks rata-ratanya 4,12 termasuk kategori Tinggi, artinya perilaku sukarela dalam diri setiap perawat untuk mencegah timbulnya masalah dengan orang 
lain sehubungan dengan pekerjaannya selalu menjaga hubungan baik dengan sesama perawat dan membuka diri untuk bertukar pikiran, berdiskusi dengan rekan kerja terkait masalah pekerjaan, belum semua perawat selalu mengingatkan rekan kerja agar tidak lupa menyelesaikan tugasnya

Tabel 3. Hasil Perhitungan Dimensi Conscientiousness

\begin{tabular}{|c|c|c|c|c|c|c|c|c|}
\hline \multirow{2}{*}{ No } & \multirow{2}{*}{ Pernyataan } & \multicolumn{5}{|c|}{ Pilihan Jawaban } & \multirow{2}{*}{ Indek } & \multirow{2}{*}{ Kategori } \\
\hline & & STS & TS & $\mathbf{N}$ & $\mathbf{S}$ & SS & & \\
\hline 1. & $\begin{array}{l}\text { Saya selalu berpikiran positif } \\
\text { terhadap kebijakan yang } \\
\text { ditetapkan lembaga Wisma } \\
\text { Harapan Asri }\end{array}$ & & & $\begin{array}{c}5 \\
(15)\end{array}$ & $\begin{array}{c}8 \\
(32)\end{array}$ & $\begin{array}{c}7 \\
(35)\end{array}$ & 4,10 & Tinggi \\
\hline 2. & $\begin{array}{l}\text { Saya selalu } \\
\text { mempertimbangkan hal-hal } \\
\text { terbaik demi kemajuan Wisma } \\
\text { Harapan Asri ke depannya }\end{array}$ & & & $\begin{array}{c}5 \\
(15)\end{array}$ & $\begin{array}{c}10 \\
(40)\end{array}$ & $\begin{array}{c}5 \\
(25)\end{array}$ & 4,00 & Tinggi \\
\hline 3. & $\begin{array}{l}\text { Saya selalu memiliki } \\
\text { semangat yang tinggi dalam } \\
\text { mencapai tujuan Wisma } \\
\text { Harapan Asri }\end{array}$ & & $\begin{array}{c}1 \\
(2)\end{array}$ & $\begin{array}{c}1 \\
(3)\end{array}$ & $\begin{array}{c}13 \\
(52)\end{array}$ & $\begin{array}{c}5 \\
(25)\end{array}$ & 4,10 & Tinggi \\
\hline 4. & $\begin{array}{l}\text { Saya merasa mampu ketika } \\
\text { harus memimpin sebuah tim } \\
\text { kerja }\end{array}$ & $\begin{array}{c}1 \\
(1)\end{array}$ & $\begin{array}{c}1 \\
(2)\end{array}$ & $\begin{array}{c}9 \\
(27)\end{array}$ & $\begin{array}{c}8 \\
(32)\end{array}$ & $\begin{array}{c}1 \\
(5)\end{array}$ & 3,30 & Sedang \\
\hline & \multicolumn{6}{|c|}{ Indeks Conscientiousness } & 3,87 & Tinggi \\
\hline
\end{tabular}

Sumber: Data primer yang diolah

\section{Dimensi Conscientiousness}

Berdasarkan tabel.3 diatas, tanggapan responden atau perawat mengenai dimensi Conscientiousness nilai indeks 3,87 termasuk kategori tinggi, artinya perilaku sukarela pada diri responden/ perawat untuk melampaui persyaratan minimum peran organisasi di bidang kehadiran, mematuhi peraturan, mengambil waktu istirahat, diterima dengan baik dan selalu berpikiran positif terhadap kebijakan yang ditetapkan lembaga dan selalu mempertimbangkan hal-hal terbaik demi kemajuan ke depannya dan para perawat memiliki semangat yang tinggi dalam mencapai tujuan Wisma Harapan Asri, walaupun demikian masih ada para perawat yang merasa belum mampu untuk memimpim tim kerja yang baik.

Tabel 4. Hasil Perhitungan Dimensi Sportmanship

\begin{tabular}{|c|c|c|c|c|c|c|c|c|}
\hline \multirow{2}{*}{ No } & \multirow{2}{*}{ Pernyataan } & \multicolumn{5}{|c|}{ Pilihan Jawaban } & \multirow{2}{*}{$\begin{array}{c}\text { Inde } \\
\mathbf{k}\end{array}$} & \multirow{2}{*}{ Kategor } \\
\hline & & STS & TS & $\mathbf{N}$ & $\mathbf{S}$ & SS & & \\
\hline 1. & $\begin{array}{l}\text { keinginan dari karyawan } \\
\text { untuk mentolerir kekurangan } \\
\text { dari kondisi ideal tanpa } \\
\text { mengeluh. }\end{array}$ & & & $\begin{array}{c}6 \\
(18)\end{array}$ & $\begin{array}{c}10 \\
(40)\end{array}$ & $\begin{array}{c}4 \\
(20)\end{array}$ & 3,90 & Tinggi \\
\hline
\end{tabular}


Praxis : Jurnal Sains, Teknologi, Masyarakat dan Jejaring | Vol. 3 | No. 2 | Maret 2021

\begin{tabular}{|l|l|c|c|c|c|c|c|c|}
\hline 2. & $\begin{array}{l}\text { Saya mudah beradaptasi } \\
\text { dengan perubahan yang } \\
\text { terjadi di Wisma Harapan } \\
\text { Asri }\end{array}$ & & $\begin{array}{c}3 \\
(9)\end{array}$ & $\begin{array}{c}13 \\
(52)\end{array}$ & $\begin{array}{c}4 \\
(20)\end{array}$ & 4,05 & Tinggi \\
\hline 3. & $\begin{array}{l}\text { Saya tidak mengeluh dalam } \\
\text { melakukan pekerjaan yang } \\
\text { menjadi tanggung jawab saya }\end{array}$ & & $\begin{array}{c}4 \\
(12)\end{array}$ & $\begin{array}{c}9 \\
(36)\end{array}$ & $\begin{array}{c}7 \\
(35)\end{array}$ & 4,15 & Tinggi \\
\hline 4. & $\begin{array}{l}\text { Saya lebih mengutamakan } \\
\text { kepentingan wisma lansia } \\
\text { meskipun akan } \\
\text { mengorbankan kepentingan } \\
\text { saya }\end{array}$ & $\begin{array}{c}2 \\
(4)\end{array}$ & $\begin{array}{c}8 \\
(24)\end{array}$ & $\begin{array}{c}(32) \\
(10)\end{array}$ & $\begin{array}{c}2 \\
(12,50\end{array}$ & Sedang \\
\hline & \multicolumn{1}{|l}{ Indeks Sportmanship } \\
\hline
\end{tabular}

Sumber: Data primer yang diolah

\section{Dimensi Sportmanship}

Dari tabel.4 diatas, tanggapan responden mengenai Dimensi Sportmanship nilai indeks 3,90 termasuk dalam kategori tinggi, artinya keinginan dari karyawan/ perawat untuk mentolerir kekurangan dari kondisi ideal tanpa mengeluh, para perawat mudah beradaptasi dengan keadaan dan perubahan yang terjadi di Wisma Harapan Asri, semua pekerjaan dilakukan dengan baik sesuai dengan tanggung jawabnya. Disisi lain hanya Sebagian perawat lebih mengutamakan kepentingan wisma lansia meskipun akan mengorbankan kepentingan pribadinya, sebagian kecil dari perawat masih mengutamakan kepentingan pribadinya.

Tabel 5. Hasil Perhitungan Dimensi Civic Virtue

\begin{tabular}{|c|c|c|c|c|c|c|c|c|}
\hline \multirow{2}{*}{ No } & \multirow{2}{*}{ Pernyataan } & \multicolumn{5}{|c|}{ Pilihan Jawaban } & \multirow{2}{*}{$\begin{array}{c}\text { Inde } \\
\mathbf{k}\end{array}$} & \multirow{2}{*}{ Kategori } \\
\hline & & STS & TS & $\mathbf{N}$ & $\mathbf{S}$ & SS & & \\
\hline 1. & $\begin{array}{l}\text { Saya sering datang lebih awal } \\
\text { ke tempat kerja, sehingga siap } \\
\text { bekerja pada saat jam kerja } \\
\text { dimulai }\end{array}$ & & $\begin{array}{c}1 \\
(2)\end{array}$ & $\begin{array}{c}1 \\
(3)\end{array}$ & $\begin{array}{c}8 \\
(32)\end{array}$ & $\begin{array}{c}10 \\
(50)\end{array}$ & 4,35 & Tinggi \\
\hline 2. & $\begin{array}{l}\text { Saya selalu berusaha } \\
\text { menyelesaikan pekerjaan } \\
\text { tepat pada waktunya }\end{array}$ & & & $\begin{array}{c}2 \\
(6)\end{array}$ & $\begin{array}{c}8 \\
(32)\end{array}$ & $\begin{array}{c}10 \\
(50)\end{array}$ & 4,40 & Tinggi \\
\hline 3. & $\begin{array}{l}\text { Saya selalu ikut berpartisipasi } \\
\text { dalam fungsi-fungsi lembaga } \\
\text { Wisma Harapan Asri }\end{array}$ & & & $\begin{array}{c}8 \\
(24)\end{array}$ & $\begin{array}{c}10 \\
(40)\end{array}$ & $\begin{array}{c}2 \\
(10)\end{array}$ & 3,70 & Tinggi \\
\hline 4. & $\begin{array}{l}\text { Saya selalu bertanggung } \\
\text { jawab terhadap tugas yang } \\
\text { diberikan kepada saya }\end{array}$ & & & $\begin{array}{c}1 \\
(3)\end{array}$ & $\begin{array}{c}10 \\
(40)\end{array}$ & $\begin{array}{c}9 \\
(45)\end{array}$ & 4,40 & Tinggi \\
\hline & \multicolumn{6}{|c|}{ Indeks Civic Virtue } & 4,21 & Tinggi \\
\hline
\end{tabular}

Sumber: Data Primer yang diolah 


\section{Dimensi Civic Virtue}

Dari tabel.5 diatas, tanggapan responden/ perawat mengenai Dimensi Civic Virtue nilai indeks 4.21 termasuk kategori tinggi, artinya perilaku dari setiap individu perawat yang menunjukkan bahwa setiap perawat bertanggung jawab, ikut berpartisipasi dan terlibat dalam dalam berbagai kegiatan serta merasa prihatin dengan kehidupan lembaga hal ini ditunjukkan dengan datang lebih awal ke tempat kerja, bekerja sesuai jam kerja dan selalu berusaha menyelesaikan pekerjaan tepat waktu. Para perawat selalu ikut berpartisipasi dalam kegiatan lembaga serta bertanggung jawab terhadap tugas yang diberika.

Berdasarkan tabel.1 sampai dengan tabel.5 diatas tanggapan responden mengenai Organizational Citizenship Behavior (OCB) dapat disimpulkan bahwa nilai rata-rata indeks 3.95 termasuk kategori tinggi, artinya responden/ perawat di lansia di Wisma Harapan Asri sudah melakukan / menerapkan OCB dengan baik, para responden/ perawat sudah melakukan tindakan ekstra yang melebihi deskripsi peran yang ditetapkan oleh lembag, perawat tidak hanya melaksanakan tanggung jawab pokoknya saja, tetapi juga bersedia melaksanakan tugas selain pekerjaan utamanya, antara lain rela membantu pekerjaan karyawan lain, memberikan pendapat dan pemikiran, suka bekerja sama, menunjukkan partisipasi aktif, memberikan pelayanan ekstra untuk orang yang dilayani dan dapat menggunakan waktu kerja secara efektif.

Berdasarkan kuesioner terbuka, jawaban responden dari ke 5 dimensi yang disertai indikatornya, dapat dilihat pada tabel dibawah ini,

Tabel 6. Rekapitulasi Jawaban Responden Kuesioner Terbuka

\begin{tabular}{|c|c|c|c|}
\hline No. & Dimensi & Indikator & $\begin{array}{c}\text { Jumlah } \\
\text { Jawaban }\end{array}$ \\
\hline 1 & Altruism & $\begin{array}{l}\text { a. Menolong rekan kerja } \\
\text { b. Bersedia meringankan pekerjaan rekan kerja } \\
\text { c. Berempati terhadap rekan kerja } \\
\text { d. Memberi perhatian pada rekan kerja }\end{array}$ & $\begin{array}{c}17 \\
7 \\
3 \\
1\end{array}$ \\
\hline 2 & Courtesy & $\begin{array}{l}\text { a. Menjaga hubungan baik dengan rekan kerja } \\
\text { b. Menghargai sesama rekan kerja } \\
\text { c. Mencegah timbulnya masalah }\end{array}$ & $\begin{array}{c}14 \\
8 \\
3\end{array}$ \\
\hline 3 & Constientiousness & $\begin{array}{l}\text { a. Mematuhi aturan-aturan di tempat kerja } \\
\text { b. Tepat waktu dalam menyelesaikan pekerjaan } \\
\text { c. Tingkat kehadiran dalam bekerja } \\
\text { d. Bekerja melebihi deskripsi kerja yang } \\
\text { ditetapkan }\end{array}$ & $\begin{array}{c}13 \\
9 \\
4 \\
3\end{array}$ \\
\hline
\end{tabular}


Praxis : Jurnal Sains, Teknologi, Masyarakat dan Jejaring | Vol. 3 | No. 2 | Maret 2021

\begin{tabular}{|c|l|l|c|}
\hline 4 & Sportmanship & $\begin{array}{l}\text { a. Tidak membesar-besarkan hal yang sepele } \\
\text { b. Kemampuan beradaptasi dengan lingkungan } \\
\text { kerja } \\
\text { c. Tidak mengeluh terhadap keadaan }\end{array}$ & 9 \\
& & & 4 \\
\hline 5 & Civic Virtue & $\begin{array}{l}\text { a. Bertanggungjawab dengan pekerjaan } \\
\text { b. Berpartisipasi dan peduli dengan organisasi } \\
\text { c. Inisiatif melakukan pekerjaan yang lebih } \\
\text { dibutuhkan }\end{array}$ & 5 \\
& & & 5 \\
\hline
\end{tabular}

Sumber: Data primer yang diolah

Berdasarkan tabel.6 diatas, jawaban responden terbayak yaitu, dimensi Altruism keutamaan yang sangat berarti adalah kerelaan para perawat untuk menolong rekan kerja untuk ikut membantu sesamanya. Pada dimensi Courtesy keutamaan yang sangat berarti adalah terjaganya hubungan yang baik antara para perawat dan karyawan lainnya dalam relasi dengan sesama perkerja. Pada dimensi Constienstiousness keutamaan yang sangat berarti adalah kesediaan para perawat untuk mematuhi peraturan kerja yang telah ditetapkan lembaga Wisma Harapan Asri maupun kebijakan dari Yayasan Mardiwijana Semarang. Pada dimensi Sportmanship keutamaan yang sangat berarti adalah para perawat tidak ingin membesar-besarkan hal-hal yang tidak begitu penting dalam urusan pekerjaan. Pada dimensi Civic Virtue keutamaan yang sangat berarti adanya tanggung jawab yang besar yang dimiliki para perawat terkait dengan pelaksanaan tugas pekerjaan yang harus dilakukan.

\section{Upaya meningkatkan Organizational Citizenship Behavior}

\section{a. Upaya meningkatkan perilaku dimensi Altruism}

Upaya yang perlu dilakukan oleh pimpinan adalah menghimbau atau mendorong beberapa perawat untuk bersedia melakukan pekerjaan bila ada perawat yang berhalangan hadir bekerja, atau bersedia untuk menggantikan rekan yang berhalangan, dan bersedia menyelesaikan tanggung jawab tanpa mengharapkan imbalan.

\section{b. Upaya meningkatkan perilaku dimensi Courtesy}

Upaya yang perlu dilakukan oleh pimpinan adalah menyampaikan kepada para perawat untuk berkomunikasi dengan baik dan saling menghargai serta mengingatkan dalam menyelesaikan tugas.

\section{c. Upaya meningkatkan perilaku dimensi Constienstiousness}

Memberi motivasi kepada para perawat supaya berani memimpin sebuah tim kerja dan mendorong kesediaan untuk bekerja melebihi deskripsi tanggung jawab kerja dari yang telah ditetapkan.

\section{d. Upaya meningkatkan perilaku dimensi Sportmanship}

Memberikan motivasi kepada para perawat agar memiliki kerelaan berkorban untuk lebih mengutamakan kepentingan melayani lansia membutuhkan kesabaran dari para perawat diwisma lansia.

\section{e. Upaya meningkatkan perilaku dimensi Civic Virtue}

Upaya yang perlu dilakukan adalah dengan melibatkan para perawat untuk ikut ambil bagian atau berpartisipasi dalam beberapa aktivitas, mendorong supaya para perawat berinisiatif melakukan pelayanan kepada para lansia untuk hal-hal yang lebih dibutuhkan. 
Upaya peningkatan pelayanan kepada para lansia

\section{a. Upaya meningkatkan ketekunan para perawat}

Para perawat mengusahakan ketekunan dalam bekerja, bertindak disiplin dalam melaksanakan tugas pekerjaan. berusaha terus menerus dengan kesabaran dalam menghadapi kondisi para lansia serta lebih sigap dalam bekerja khususnya pada waktuwaktu tertentu di mana terdapat kesibukan yang banyak dalam waktu bersamaan, sehingga pelayanan untuk para lansia dapat tertangani.

b. Upaya meningkatkan interaksi memperhatikan lansia

Para perawat berusaha menumbuhkan kepedulian kepada warga lansia yang dilayani ini, meningkatkan interaksi dengan lansia agar merasa lebih diperhatikan, lebih mengenali kepribadian setiap lansia, sehingga dapat mendampingi dengan menyesuaikan keadaan pribadi masingmasing lansia.

c. Upaya meningkatkan kualitas pelayanan sebagai perawat untuk lansia. Para perawat berusaha memberikan hal terbaik dalam pelayanan, dilakukan melalui usaha menjalin hubungan yang dekat antar pribadi perawat dengan para lansia, membantu bila lansia mengalami keterbatasan serta untuk beradaptasi dengan keadaan fisik yang tua.

\section{d. Upaya meningkatkan arah tindakan keperawatan yang tepat}

Para perawat berusaha membimbing para lansia untuk dapat melakukan aktivitas dalam kesehariannya, dianggap sebagai sahabat, keluarga maupun sebagai motivator.

\section{e. Upaya meningkatkan pendekatan dalam hubungan dengan lansia}

Para perawat berusaha meningkatan pelayanan kepada para lansia dengan pendekatan secara psikologis dengan kerelaan mendengarkan keluhan dan curahan hati para lansi, adanya komunikasi antara perawat dengan para lansia untuk memahami dan menampung keinginan lansia. Membantu lansia menjaga kebugaran fisik, seperti mengajak berolahraga ringan sesuai kemampuan lansia dan mengajak untuk beraktivitas secara lebih mandiri.

\section{Upaya Wisma Harapan Asri meningkatkan $O C B$ dan pelayanan}

a. Pimpinan Wisna setiap bulan mengadakan pertemuan bersama dengan para perawat, melakukan evaluasi mengenai kinerja para perawat serta memberikan masukan dan memberikan motivasi untuk bekerja lebih baik dalam melayani para lansia.

b. Adanya pertemuan masing-masing perawat dengan pimpinan pada awal bulan mengenai evaluasi kinerja masingmasing perawat. setiap perawat diberi kesempatan juga untuk menyampaikan keadaan diri masing-masing berkaitan dengan tugas, keluhan dan hambatan yang dialami. Pimpinan wisma memberikan peneguhan kepada masingmasing perawat agar dapat melaksanakan tugas kerja dengan lebih baik, memberikan solusi atas hambatan yang dialami. Selain itu juga pimpinan memberi masukan agar para perawat bekerja dengan penuh kedisiplinan, mempunyai kepekaan, menghargai lansia dan karyawan lain, dan bertanggung jawab melaksanakan program kegiatan wisma.

c. Pelaksanaan program pengembangan SDM berupa pelatihan keperawatan dengan narasumber yang berkompeten. Materi pelatihannya adalah metode perawatan orang sakit dengan narasumber staf pengajar STIKES Elisabeth Semarang. Materi pelatihan bimbingan pendampingan psikologis lansia dengan narasumber staf pengajar Fakultas Psikologi Unika Soegijapranata Semarang. Materi pengetahuan tentang penyakit dalam dengan narasumber dokter spesialis dari Rumah Sakit Elisabeth Semarang. 
d. Pengelola menyelenggarakan pembinaan kerohanian untuk para perawat dan karyawan lainnya dalam bentuk rekoleksi yang dilaksanakan tiga kali dalam setahun.

\section{Upaya para perawat meningkatkan $O C B$ dan pelayanan}

Berikut ini upaya-upaya yang dilakukan para perawat untuk lansia Wisma Harapan Asri dalam meningkatkan perilaku $O C B$ dan peningkatan pelayanan pendampingan lansia, antara lain:

a. Kesediaan bekerja sama diwujudkan dalam bentuk menolong pekerjaan sesama rekan agar semua tanggung jawab untuk mendampingi lansia dapat terselesaikan.

b. Meningkatkan ketekunan dalam bekerja berupa sikap kesetiaan melaksanakan tanggung jawab di tempat kerja dan selalu berdisiplin dalam tugas pekerjaan.

c. Menjalin hubungan yang dekat dengan setiap penghuni lansia, menjadi sahabat dan kesediaan selalu siap membantu kebutuhan para lansia.

d. Mengikuti pembinaan kerohanian yang diberikan pengelola Wisma Harapan Asri.

\section{PENUTUP}

\section{Kesimpulan}

Berdasarkan hasil analisis data dan pembahasan Organizational Citizenship Behavior $(O C B)$ para perawat untuk lansia di Wisma Harapan Asri Semarang, dapat diambil kesimpulan sebagai berikut:

1. Deskripsi Organizational Citizenship Behavior $(O C B)$ para perawat untuk lansia di Wisma Harapan Asri pada kelima dimensi $O C B$ yakni: pada dimensi Altruism, menunjukkan tingkat kategori "sedang", sedangkan pada dimensi Courtesy, Conscientiousness, Sportmanship, dan Civic Virtue menunjukkan tingkat kategori "tinggi". Secara keseluruhan para perawat sedah melakukan OCB.

2. Upaya peningkatan perilaku kelima dimensi $O C B$ yakni:

a. Dimensi Altruism: Memberi himbauan kepada para perawat untuk bersedia melakukan pekerjaan rekan yang berhalangan hadir bekerja dan menumbuhkan kesadaran dalam bekerja serta menumbuhkan empati.

b. Dimensi Courtesy: Memberi masukan untuk sering berkomunikasi mengingatkan rekan pada tugas kerja dan menjaga hubungan baik dengan sesama karyawan.

c. Dimensi Constienstiousness: Memberi dorongan untuk mampu memimpin tim kerja dan kesediaan bekerja melebihi tanggung jawab dari yang telah ditetapkan.

d. Dimensi Sportmanship: Memberi masukan agar rela berkorban mengutamakan kepentingan wisma lansia dan bertoleransi terhadap keadaan fisik-psikologis lansia.

e. Dimensi Civic Virtue: Melibatkan para perawat ikut ambil bagian atau berpartisipasi dalam aktivitas penting lembaga ini dan dorongan untuk berinisiatif serta peduli terhadap karya pelayanan wisma lansia.

3. Usaha mengembangkan pelayanan para perawat agar kebutuhan para lansia dapat terpenuhi dengan baik antara lain:

a. Mengupayakan ketekunan para perawat melalui kesetiaan dan kesabaran menghadapi lansia serta cekatan dalam pelayanan.

b. Mengupayakan interaksi memperhatikan lansia melalui kepedulian, pengenalan kepribadian dan penyesuaian keadaan lansia.

c. Mengupayakan kualitas pelayanan sebagai perawat dengan menjalin hubungan yang dekat, memberi 
Praxis : Jurnal Sains, Teknologi, Masyarakat dan Jejaring | Vol. 3 | No. 2 | Maret 2021

perhatian dan membantu keterbatasan lansia.

d. Mengupayakan tindakan keperawatan yang tepat dengan mengoptimalkan kondisi lansia dan membimbing supaya dapat melakukan aktivitas harian.

e. Mengupayakan pendekatan hubungan dengan lansia dalam proses pengasuhan melalui pendekatan psikologis yakni adanya komunikasi aktif perawat dengan lansia dan pendekatan fisik yakni membantu kebugaran fisik lansia.

\section{Saran}

Berdasarkan hasil penelitian maka peneliti memberikan saran antara lain :

1. Bagi Wisma Harapan Asri

Pengelola Wisma Harapan Asri perlu mempertahankan pembinaan kepada para perawat melalui pertemuan evaluasi bulanan, pembinaan secara pribadi dan pembinaan kerohanian dengan memberikan dorongan serta himbauan untuk menjaga kualitas pelayanan dan mempertahankan perilaku Organizational Citizenship Behavior dengan kelima dimensi $O C B$ dalam bekerja. Bagi para perawat untuk lansia

2. Para perawat hendaknya bersedia mengikuti pelatihan dari narasumber ahli keperawatan maupun dokter dan pembinaan kerohanian yang diberikan pengurus.

\section{DAFTAR PUSTAKA}

Ahdiyana, Marita, (2010). Dimensi Organizational Citizenship Behavior $(O C B)$ dalam Kinerja Organisasi. Jurnal Ilmu Administrasi No.1 Volume $X$ Universitas Negeri Yogyakarta. https://journal.uny.ac.id/index.php/efis iensi/article/view/3965
Aisyia, Lidya, (2009). Hubungan Antara Iklim Organisasi Dengan $O C B$ Guru dan Tenaga Kependidikan di SDIT AlQalam Depok. Skripsi, UIN Syarif Hidayatullah Jakarta.

http://repository.uinjkt.ac.id/dspace/ha ndle/123456789/28359

Akira, \& Jatmika, Devi, (2015). Organizational Citizenship Behavior $(O C B)$ Pada Perawat di Rumah Sakit Ibu dan Anak "X" di Bandung. Jurnal Vol 8 No.1 Program Studi Psikologi Universitas Bunda Mulia. https://journal.ubm.ac.id/index.php/psi bernetika/article/view/487

Budiansyah, Yusef, dkk. (2017). Pengembangan Model Organizational Citizenship Behavior (OCB) Dalam Rangka Meningkatkan Kinerja Universitas Swasta Di Ciamis, Garut, Dan Kuningan. Jurnal SMART - Study \& Management Research Vol XIV, No 3-2017.

http://stiestembi.ac.id/file/4.\%20Yusep\%2 0Budiansyah,\%20Shendy\%20Amalia, \%20Vina\%20Marinda.pdf

Dewi, Sofia Rhosma, (2014). Buku Ajar Keperawatan Gerontik. Yogyakarta: Deepublish. https://books.google.co.id/books?id=3 FmACAAAQBAJ

Kholifah, Siti Nur, (2016). Keperawatan Gerontik. Kementrian Kesehatan Republik Indonesia: Pusat Pendidikan Sumber Daya Manusia Kesehatan, Badan Pengembangan dan Pemberdayaan Sumber Daya Manusia Kesehatan.

http://bppsdmk.kemkes.go.id/pusdiksd mk/wp-

content/uploads/2017/08/Keperawatan -Gerontik-Komprehensif.pdf

Kuntjorowati, Elly, (2017) Nyaman dan Tentram di Rumah Pelayanan Lanjut Usia. Jurnal PKS Vol 16 No 2 Balai Besar Penelitian dan Pengembangan Pelayanan Kesejahteraan Sosial (Babeslitbang Yankesos). https://ejournal.kemsos.go.id/index.ph $\mathrm{p} / \mathrm{jpks} /$ article/view/1390 
Praxis : Jurnal Sains, Teknologi, Masyarakat dan Jejaring | Vol. 3 | No. 2 | Maret 2021

Nurdin, Nurul C., \& Haris H., (2017) Studi Tentang Pelayanan Kesejahteraan Warga Panti Sosial Trena Werdha Gau Mabaji di Kecamatan Bontomaranu Kabupaten Gowa. Jurnal Universitas Negeri Makasar https://ojs.unm.ac.id/index.php/tomale bbi/article/view/3720/2132

Nurfatimah, Rosita, Melly S., Yoyoh J., (2017). Perancangan Program Pendampingan Lanjut Usia Berbasis Home Care Di Posbindu Kelurahan Geger Kalong. Jurnal Vol III No.2 Oktober 2017 Prodi Pendidikan Kesejahteraan Keluarga, Departemen PKK FPTK UPI. https://ejournal.upi.edu/index.php/fami lyedu/article/view/8809

Purnomo, Rohmat Aldy (2017). Analisis Statistik Ekonomi dan Bisnis Dengan SPSS. Ponorogo: Wade Group Unmuh Ponorogo Press.https://books.google.co.id/books ?id=MQCGDwAAQBAJ\&pg

Sartika, Iik, (2019), Organizational Citizenship Behavior $(O C B)$ Karyawan di Unit Rekam Medis Rumah Sakit Swasta X. Jurnal Manajemen Informasi dan Administrasi Kesehatan (JMIAK) 2 (01) Universitas Veteran Bangun Nusantara.

https://scholar.google.com/citations?us er=FdJaAmUAAAAJ\&hl=id

Setyaningrum, Nuraeni, (2012). Upaya

Peningkatan Pelayanan Sosial Bagi Lansia Melalui Home Care Service di Panti Sosial Tresna Werdha (PSTW) Yogyakarta Unit Budhi Luhur. Skripsi Fakultas Ilmu Pendidikan Universitas Negeri Yogyakarta https://eprints.uny.ac.id/27076/1/Nura eni\%20Setyaningrum.pdf

Sulastri, Sri, \& Humaedi, S., (2017). Pelayanan Lanjut Usia Terlantar Dalam Panti. Jurnal Riset \& PKM Vol. 04 No. 01 Universitas Padjajaran. http://jurnal.unpad.ac.id/prosiding/arti cle/view/14225

Undang-Undang Republik Indonesia Nomor 13 Tahun 1998, tentang
Kesejahteraan Lanjut Usia http://www.bphn.go.id/data/documents 198uu013.pdf

Waspodo, Agung AWS., \& Lussy Minadaniati, (2012) Pengaruh Kepuasan Kerja dan Iklim Organisasi Terhadap Organizational Citizenship Behavior $(O C B)$ 